\title{
Rubrics: Road Maps to Being Successful
}

\author{
Barba Aldis Patton \\ University of Houston-Victoria \\ USA
}

\begin{abstract}
There are rubrics and there are rubrics. 'Road Maps to being Successful' is an attempt to provide teachers (evaluators) with guide lines on how to prepare rubrics. One can make simple yet valid rubrics or make complex ones which require too much time for the classroom teacher to use. Discussion will be spent on making the rubrics for any discipline and as transparent as possible in order to have a high level of fairness to all involved. Sample of a beginning rubric is included.
\end{abstract}

\section{Introduction}

Remember when you were a child and you loved to go on treasure hunts? Using the clues, you and your friends ran all around the neighborhoods trying to find the next clue. Rubrics, just as those clues helped you locate the end treasure, can be your roadmap to success in many academic environments. They can be your guide to being successful in your classrooms and in your evaluations of your students, as well as the students' evaluations of you. That success can and will lead to students being more academically prepared. [1]

\section{What is a Rubric?}

A rubric is a document which can provide an assessment of a given work. That work might be in the form of a manuscript in progress, one which has been completed and is being submitted for publication, etc. if one is using the rubric in an academic setting or it could be something similar to a checklist when a program is being evaluated. Furthermore it could even be that checklist one's physician uses when you go in for an annual healthy person checkup

Usually the rubrics will have scales and criteria with ranges from not observed to over the top in excellence. Checklist could be considered very simple uncomplicated rubrics which only have dichotomous answers. [2]

\section{Importance of Rubrics}

If a rubric is to be one used with a high degree of reliability, it absolutely must be one that is evaluating the needs of all, etc. If it does not evaluate the items which need to be evaluated it is of no value to anyone. As a wise man once said, "you have to ask the right question if you expect to get an answer for the problem you are trying to solve."

Rubrics like any instrument of measure need to have rater reliability. When there is rater reliability training the consistency and validity of the rubric increases [3] [4]. Rubrics can be one of the most useful tools when preparing a manuscript however, many have serious flaws and the writer must be careful to selection the one with instructional quality.

\section{Where should Rubrics be used}

Rubrics should be used in as many aspects of the academic world as possible, however, it seems to be lacking in a number of areas. Rubrics have a special place in the classrooms, from the beginning elementary grades through graduate studies. While there are pros and cons about the use of rubrics, the academic world needs a way to evaluate its activities. From the classroom to the manuscripts, rubrics can and should play an important part. Jonsson [5] found rubrics when used as intended as a scoring instrument can make a difference in the reliability, validity and educational aspects.

University pre-service teachers often use a rubric as a checklist to be sure they have included all the components of a given activity. This is especially true if it is an activity which has new aspects and the student is unsure of the various aspects. An example might be a portfolio and this is the first time the student has prepared a portfolio of this type. [6]

\section{Guidelines to Preparing Rubrics}

While there are many ways to prepare rubrics, one of the easiest and best way as espoused by the author is to start by listing all the characteristics of a perfect 
item or document which you desire to evaluate. Think. What would be a perfect submission? This list will now form your criteria and desired traits you wish to have in your rubric. If you work backwards from the perfect to the less than perfect you will have the various degrees from the total lack of understanding the problem to the perfect solution. Working backwards is a strategy used by Polya [7] as well as Stein, Grower and Menningsen[8] and later Patton[9]. Polya used the strategy in his early work on math problem solving. At the time it differed much from other works. Most teachers seemed to be looking for more clarity in the strategies for teachers and as a result were quick to promote Polya's work. It is best to have an odd number on the range just as on a Likert scale. It helps to keep the scores in more prospective and does not force the evaluator to give or deduct credit when the item being evaluated is truly neutral [9].

W. James Popham, who is a highly known authority in the field of educational assessment has a few warnings for the new researcher and writer when preparing rubrics [4]. One is that the rubric needs to have task specific evaluation and it should be evaluating performances which are instructional relevant. Secondly, Popham believes the criteria needs to be focused however; it should give some room for creativity. Some rubrics list so many checkpoints that it becomes a toss-up between a nightmare and a good laugh. Above all, Popham and others believe rubrics should be a guide to teachers and evaluators and not overwhelm them. Schmoker's [10] can be a strong influence when working on rubrics. He advocates that rubrics be developed in a format which would pass any test of fairness and transparency which will in turn provide reliability and validity.

See Table 1 in the appendix for an example of the steps to begin a rubric. It is definitely not a complete way to evaluate the development of a question for a problem solving activity. This activity asks a student to develop.

\section{Implementation of Rubrics}

Implementation can be easy or it can be one of the most challenging parts of evaluations in a classroom.

\section{Conclusions}

Rubrics can be of great value to both the person who is preparing an academic artifact for evaluation and the evaluator. For the first it can be used as a checklist to determine if all aspects are included in the artifact and for the evaluator it can assure him/her that all the artifacts are being judged by the same standards. The rubric adds a high degree of validity and reliability. [10] Hopefully academic readers will be able to learn to start with simple rubrics and advance to complex ones. With this new or additional skill/s he/she will be developing rubrics for all academic tasks.

\section{References}

[1] M. Connelly \& K. Wolf. "The Art of Rubrics: Paining by Numbers?" Teaching Artist Journal Lawrence Erilbaum. 2007 5(4) pp. 279-288.

[2] H. Jeong, "What is your teacher rubric? Extracting teachers' assessment constructs". Practical Assessment Research and Evaluation. 2015. pp. 1-13.

[3] J. A. Arter \& J.Chappnis. "Creating and recognizing quality rubrics”. Pearson: Boston 2006.

[4] W. J. Popham."What's wrong and what's right with rubrics" Educational Leadership. 1997. 55 pp 72-75.

[5] A. Jonsson, "Rubrics as a way of providing transparency in assessment"Assessment \& Evaluation in Higher Education. 2014. 39(7) pp840-852.

[6] Saiz, C., Rivas, S. F. \& S Olivares, (2015) "Collaborative learning supported by rubrics improves critical thinking". Journal of the Scholarship of Teaching and Learning. 15 (1) pp. 10-19.

[7] J. Polya "How to solve it: A new aspect of mathematical method". 1988 (2nd Ed.) Princeton: Princeton University Press.

[8] M.K Stein, B. W. Grower \& M. Henningsen. "Building students capacity for thinking and reasoning: An analysis of mathematics tasks used in reform classrooms". 1996 American Educational Research Journal 33(2) 455-488.

[9] B. A. Patton. Rubrics can be used to gain publication in journals." National Social Science Association conferences, 2016.

[10] Schmoker, M. (2009). Measuring What Matters.Educational Leadership. 70-72. 


\section{Appendix}

Table 1. Steps to begin a rubric

\begin{tabular}{|c|c|c|c|c|}
\hline Trait & 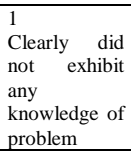 & $\begin{array}{l}2 \\
\text { Met some of } \\
\text { the } \\
\text { expectations } \\
\text { but clearly } \\
\text { not all. }\end{array}$ & $\begin{array}{l}3 \\
\text { Met high } \\
\text { expectations } \\
\text { for this trait. }\end{array}$ & rating \\
\hline $\begin{array}{l}\text { All needed } \\
\text { information } \\
\text { included }\end{array}$ & & & yes & 3 \\
\hline $\begin{array}{l}\text { Problem } \\
\text { requires } \\
\text { regrouping } \\
\text { (uses } \\
\text { numbers } \\
\text { greater than } \\
\text { 9) }\end{array}$ & & yes & & 2 \\
\hline $\begin{array}{l}\text { Problem } \\
\text { requires } \\
\text { more than } \\
\text { one } \\
\text { computation }\end{array}$ & & & yes & 3 \\
\hline $\begin{array}{l}\text { Question } \\
\text { clearly stated }\end{array}$ & & & yes & 3 \\
\hline total & & & & 11 \\
\hline
\end{tabular}

Dior is a little poodle who loves to play with stuffed ducks. She had five and received four more for her birthday. She took one in the yard to play and lost it. How many little ducks does Dior have now? $5+4=9 ; 9-1=8$

Dior now has 8 little stuffed ducks.

The above table is a small example of how to develop rubrics for a specific math situation. More rubrics will be developed in future writings. [9]. The sample above has the person earning 11/12 which would compute to $92 \%$. By simply dividing the number earned by the total possible, a percentage is derived. This helps to move from just the number of items which divide into 100 evenly. 